\title{
ASPECTOS METAFÍSICOS DO IDEALISMO EM HUSSERL ${ }^{1}$
}

Martina Korelc (UFG) ${ }^{2}$

martina.ufg@gmail.com

Resumo: No presente texto argumento que, na medida em que implica uma compreensão do ser, há um aspecto metafísico no idealismo de Husserl; apresento como Husserl pensa a relação entre o ser e o pensamento, e o sentido do ser que resulta disso, tanto para a consciência que é considerada a esfera originária do ser, como para o ser dos entes mundanos, cujo sentido é constituído pela vida da consciência. É apenas o idealismo transcendental que, para Husserl, elucida o sentido originário do ser, tanto em função das exigências epistemológicas, como também em função das exigências práticas. No fim apresento o sentido do ser como ato de ser, proveniente da tradição metafísica aristotélico-tomista, como uma possibilidade de pensar para além do idealismo de Husserl.

Palavras-chave: idealismo, metafísica, ser, pensamento.

A questão do idealismo de Husserl é difícil e controversa; o seu sentido rendeu na história da fenomenologia muitas interpretações diferentes, opostas entre si, e isto já no tempo de vida de Husserl. Isto é devido também ao fato de haver ambiguidades nos textos de Husserl. Ele mesmo sempre se sentiu incompreendido por aqueles que levantaram argumentos contra o idealismo, e esta objeção da nãocompreensão do autêntico sentido do idealismo de Husserl ainda é levantada contra os que não concordam com ele.

\footnotetext{
${ }^{1}$ Recebido: 09-08-2016/ Aceito: 16-08-2016/ Publicado on-line: 28-08-2016.

${ }^{2}$ Martina Korelc é Professora Adjunta IV na Faculdade de Filosofia da Universidade Federal de Goiás, Goiânia, GO, Brasil.
} 
Para poder elucidar o seu sentido, é valioso começar por elucidar o que o idealismo de Husserl não é. Nas palavras de Husserl, o seu idealismo, chamado de fenomenológico-transcendental, não se opõe a nenhum realismo, não lhe é possível filosoficamente, com argumentos e com sentido, opor nenhum realismo (Hua V, p. 150). Não se trata de pôr em questão a existência do mundo real, esta é indubitável. Se realismo significa afirmar a existência do mundo, Husserl se diz um realista ${ }^{3}$, mas isto não está em oposição, para ele, com o idealismo transcendental; isto deve significar também que a afirmação da existência do mundo não é uma tese filosófica. Tampouco se trata de afirmar que é a consciência, ou o sujeito, a "produzir" o mundo. O que está filosoficamente em questão é o sentido desta existência, o sentido do ser do mundo e do ser da subjetividade, bem como a relação entre eles. O idealismo tem a ver com a concepção do ser, e é sobre isto que pretendo refletir no presente texto. Pretendo apresentar brevemente como Husserl pensa o sentido do ser na sua fenomenologia transcendental e aproximar, ao final, este sentido de ser em Husserl à noção de ser aristotélico-tomista, porque este sentido, num determinado aspecto, parece-me mais radical.

Poderia questionar-se a pertinência da qualificação deste idealismo como metafísico. Há, entre os intérpretes desta questão - e antes disso no próprio Husserl -, um esforço valioso de sublinhar a originalidade da sua posição, destacando-a das outras concepções do idealismo na história de

\footnotetext{
${ }^{3}$ Cfr. Hua VI, p. 190-191/153: "De antemão, está o mundo, que permanece sempre previamente dado e indubitável na certeza de ser e na autoconfirmação. [...] Não pode, por isso, haver realismo mais forte, se esta palavra não diz mais do que: 'estou certo de que sou um homem que vive neste mundo etc., e disto não duvido minimamente'. Mas compreender esta obviedade é, precisamente, o grande problema”.
} 
filosofia; neste sentido há a interpretação de que é necessário distinguir entre um idealismo epistemológico e idealismo metafísico; o de Husserl seria um idealismo epistemológico compatível com o realismo metafísico. ${ }^{4} \mathrm{~A}$ preocupação constante de Husserl com as questões epistemológicas, com a crítica da razão e com o tema da ciência radical e fundamentadora, como desenvolvimento do método desta ciência, corroboram esta interpretação.

Encontramos, porém, em Husserl também reflexões sobre a metafísica, diversas tentativas de defini-la e de explicitar a sua relação com a fenomenologia; aqui não é possível expô-las com devida atenção e precisão, o que por si exigiria um outro estudo. ${ }^{5}$ Desde as primeiras obras de Husserl é possível notar sua preocupação de definir o campo da metafísica e de precisar a sua relação com as ciências e, mais tarde, com a fenomenologia. No curso "Allgemeine Erkenntnistheorie" de 1902/1903, por exemplo, o autor escreve que as ciências têm grande necessidade da metafísica, pois a metafísica é aquela ciência que oferece o conhecimento último e mais profundo da realidade e que investiga "o que pertence aos entes no mais profundo, e intrinsecamente relacionadas com isso[...] estão as questões sobre os princípios mais altos do conhecimento que nos possibilitam alcançar a verdade real" (HuaMat III, p. 245). A questão sobre o ser e sua relação com o conhecimento é para Husserl essencialmente uma questão metafísica. Também na definição da metafísica que é dada no texto A ideia

\footnotetext{
${ }^{4}$ Refiro-me à interpretação do prof. Pedro Alves, de quem tive oportunidade de aprender muito sobre Husserl. Semelhante interpretação, sem contudo explicitamente estabelecer a distinção entre idealismo ou realismo epistemológicos e metafísicos, defende também prof. Carlos Alberto Ribeiro de Moura no célebre e importante texto Crítica da razão na fenomenologia.

${ }^{5}$ Veja-se, por exemplo, GHIGI 2007.
} 
da Fenomenologiase pode depreender-se o mesmo - embora neste texto seja acrescentada a distinção entre o ser enquanto considerado pelas ciências e o ser considerando no sentido absoluto: uma vez que as ciências naturais não são ciências definitivas do ser, a metafísica é a ciência do ente no sentido absoluto, que brota da crítica do conhecimento; esta crítica seria uma parte primeira e fundamental da fenomenologia (Hua II, p. 23), com a qual Husserl começou suas reflexões, desconsiderando as metas metafísicas da crítica do conhecimento. As questões metafísicas entraram, portanto, cedo nas suas reflexões ${ }^{6}$ e permaneceram vigentes até as últimas obras; lemos de fato também na obra Crise das ciências europeias e a fenomenologia transcendental que a metafísica é a ciência das questões supremas e últimas, dos problemas da razão, às quais as ciências positivas não podem responder e cujo espírito proporciona sentido último a todos os conhecimentos (Hua VI, p. 6); e o problema supremo é o do sentido. Considero, portanto, que a reflexão de Husserl sobre o ser, a questão sobre o sentido absoluto do ser é uma questão metafísica; neste sentido o idealismo de Husserl, na medida em que diz respeito ao problema do ser, encerra uma dimensão metafísica.

\section{SER ENQUANTO SER CONHECIDO}

A relação entre as questões sobre o ser e as questões epistemológicasé estreita e essencial - como em toda a tradição da metafísica, assim também nas reflexões de Husserl.

\footnotetext{
${ }^{6}$ Confronte-se também, por exemplo, o texto no 11 da Hua XLII, de 1908, que trata precisamente da metafísica fundada transcendental-fenomenologicamente. O seu primeiro nível é retroceder ao primeiro absoluto que é a consciência; um segundo nível trata da unidade das múltiplas mônadas através da teleologia (Hua XLII, p. 164).
} 
Landgrebe, por exemplo, afirma que das análises fenomenológicas não pode resultar qualquer posição metafísica; ao contrário, a orientação da metafísica está fixada pelas opções metodológicas fundamentais (1963, p. 100), referindose certamente à ideia husserliana da ciência rigorosa que prescreve o método da redução fenomenológica. O próprio Husserl, de fato, relaciona o seu idealismo à redução fenomenológica: "O itinerário para o idealismo transcendental encontra-se pré-indicado, em última análise, já na redução fenomenológica, compreendida corretamente, como pois a fenomenologia inteira não é nada outro que a primeira forma rigorosamente científica desse idealismo" (Hua VIII, p. 181). O que motivou a elaboração do método da redução foi o ideal da ciência rigorosa que exige a fundamentação radical, definitiva do conhecimento; é à luz deste ideal que o conhecimento das ciências naturais não é um conhecimento definitivo dos entes e exige uma crítica, uma reflexão sobre a relação entre o conhecimento e os entes, ou dito de modo mais geral, entre o pensamento e ser. O que interessa à ciência radical que a fenomenologia pretende ser é o ser enquanto é verdadeiro (Hua XLII, p. 229), isto pressupõe que seja conhecido e atestado pela razão. Todo o conhecimento, ou todo o pensamento e as afirmações sobre o ser, devem atestar-se e justificar-se no próprio pensamento, sem que um ser qualquer deva se lhe antepor ou opor (Hua XXXVI, p. 41). O ser, portanto, não é um ponto de partida imediato; ele é considerado enquanto se manifesta à consciência, acessado pela percepção no caso do ser real transcendente e, na medida em que se expressa na predicação, determinado pela razão, ou seja, pelos juízos que lhe dão validade. Que a pergunta pelo modo de ser seja para Husserl estreitamente relacionada à pergunta pelo acesso ao seu co- 
nhecimento, se evidencia, por exemplo, pelo procedimento de Husserl nas Ideias I e nos textos anteriores a esta obra de obter o sentido da transcendência dos objetos mundanos a partir da análise da percepção enquanto esta é o acesso originário a eles .

Esta relação estreita entre o ser e o seu conhecimento em Husserl implica que, mesmo que a análise fenomenológica pretenda partir das coisas mesmas, sem nenhum pressuposto a respeito delas, estas só podem ser consideradas tal e na medida em que elas nos são originariamente dadas no pensamento, no "fórum" perante o qual elas podem ser atestadas, na intuição. O sentido do ser tem portanto a ver com a atestação deste ser no pensamento .

\section{A ORIGEM DO CONCEITO DE SER}

Refletindo sobre como obtemos o conceito do ser, no curso mencionado de 1902/1903, pensando explicitamente a insuficiência das ciências empíricas de esclarecerem até o fim a realidade, isto é, o ser real, Husserl o relaciona com a percepção dos objetos: a origem do conceito do ser, ou do seu significado, está na experiência do preenchimento adequado das intenções, que visam o ser; uma coisa é percebida como dada realmente, como sendo ou existindo, quando a intenção é preenchida; o ser é o que dá plenitude à intenção que o visa (HuaMat III, p. 134). Ser, para um objeto, entretanto, não significa precisamente ser percebido, porque ser percebido é um fato distinto do fato da mera existência [Existenz], diz Husserl; sem percepção, porém, não temos nenhum conceito de existência; um ser não perceptível é sem sentido. Por isso é preciso considerar como uma verdade evidente que o conceito da existência deve ser en- 
contrado no sentido da percepção. (HuaMat III, p. 136). O ser verdadeiro implica, entretanto, a adequação ao intelecto, isto é, a uma intenção que visa e põe o objeto inicialmente pela posição da crença; o ser verdadeiro é a identidade entre o que é visado e o que é efetivamente dado no modo de preenchimento.

Ora, de acordo com o que foi dito acima sobre a necessidade de o ser se atestar no pensamento, em toda a reflexão husserliana sobre o ser opera um princípio epistemológico que é a base para a argumentação a favor do idealismo transcendental, chamado pelos editores do volume sobre o Idealismo transcendental de "princípio de legitimação" [das "Prinzip der Ausweisbarkeit"]. Na sua forma mais geral este princípio diz que a posição de algo como sendo, existindo, é legitimada ou racional quando é por princípio possível que o ente posto como existindo se mostre ou legitime como tal (Hua XXXVI, p. XV). Numa das formulações do princípio Husserl diz: "A proposição 'A existe' e a proposição 'Há um caminho para construir a atestação possível da existência de A', 'Existe a possibilidade ideal e visível de tal atestação' são equivalentes. Assim, em geral as ideias 'verdade' e 'possibilidade ideal de atestação visível' são ideias equivalentes” (Hua XXXVI, p. 73). Neste sentido, Husserl identifica a possibilidade de algo ser dado no pensamento e de assim se legitimar como essencial ao ser: "À essência do ser pertence poder-ser-dado e poder-serdado-legitimamente-(perfeitamente?)” (Hua XXXVI, p. 32) .

Em vários textos de Husserl encontramos a distinção entre a mera coisa e a coisa enquanto considerada no seu ser. Os predicados ser e não ser se aplicam ao sentido objetivo e não aos meros objetos [Gegenständeschlechthin], diz Husserl nas Meditações Cartesianas (Hua I, p. 91). 
Nas reflexões husserlianas consideradas até aqui, parece-me que, ao falar sobre o ser, Husserl às vezes tem em mente a existência de um objeto, e noutras vezes o próprio objeto no seu ser, ou seja, o ente, a coisa que é e suas características essenciais. Não encontrei nenhum esclarecimento de Husserl a respeito dessa distinção metafísica tradicional que remonta a Boécio e é aprofundada por Tomás de Aquino. Há, porém, em Husserl a distinção, também clássica, entre existência e essência, ou entre o ser individual fatual e essencial. A respeito disso Husserl escreve em Die Idee der Phänomenologie que a oposição entre a existência e essência não significa outra coisa que dois modos de ser que se anunciam em dois modos de autodoação (Hua II, p. 70).

Por causa da exigência da fundamentação radical, a fenomenologia enquanto ciência fundamentadora não pode satisfazer-se com as coisas intuídas empiricamente e assim com a existência fática e individual de objetos; a crítica mostra a insuficiência epistemológica da intuição empírica para fins da fundamentação absoluta, apontando a necessidade da intuição das essências e da reflexão; o sentido do ser empírico contudo deverá ser explicitado. No texto Fenomenologia como ciência de rigor, de 1911, Husserl afirma que a fenomenologia enquanto ciência pura não faz uso da posição existencial dos entes da natureza, que é necessariamente individual, pois ela é uma investigação das essências, do ser de essência [Wesenssein], e não uma investigação da existência [Daseinsforschung] (Hua XXV, p. 33-36).

\section{SENTIDO OBJETIVO E SER ABSOLUTO}

O texto $\mathrm{n}^{\circ} 2$ da obra Transzendentaler Idealismus, de 1908, oferece uma reflexão de Husserl a respeito do que 
significa, precisamente, perguntar sobre o ser dos objetos. O problema do 'ser em si' dos objetos empiricamente perceptíveis e da relação deles com o pensamento é uma questão central à qual o autor se dedica nesse texto, como em vários textos deste período, discutindo a teoria da percepção. $O$ pensamento natural, diz o autor, e a ciência natural enquanto a forma mais desenvolvida dele, dizem o que são os objetos ou a objetualidade, qual é o seu conteúdo, ou sentido objetivo, seja no sentido mais geral, seja considerando diferentes tipos de objetos, como coisas, números... Mas perguntar sobre o sentido dos objetos enquanto unidade de conhecimento é outra questão que não toca estas ciências; é perguntar sobre a relação dos objetos com o conhecimento, sobre como se devem compreender a legitimidade e a validade das posições de ser no conhecimento. Para poderem ser dados, conhecidos, os objetos devem ser algo "no pensamento" e o sentido da sua transcendência em relação ao pensamento, do seu "ser em si", deve ser esclarecido. Perguntar sobre o sentido do 'ser em si' dos objetos é verificar se os objetos conhecidos têm uma relação essencial à consciência, se são relativos a ela; isto é questionar sobre a possibilidade de eles serem considerados como sendo absolutamente. Trata-se de uma pergunta sobre o ser absoluto e sobre o que o ser absoluto é por essência. Husserl distingue, portanto, entre o sentido objetivo ou o ser objetivo e o sentido deste ser objetivo, que é o sentido ou o ser último; o ser no sentido objetivo não é um ser último. Este, ser no sentido absoluto, só pode ser alcançado pela redução fenomenológica e pela consideração metafísica. É o metafísico que pergunta pelo ser absoluto (Cfr. XXXVI, p.22; 33). Trata-se, na verdade, do ser do sentido.

Neste texto referido acima, o texto no 2 publicado na 
obra Transzendentaler Idealismus, de 1908, há portanto uma distinção clara entre a coisa material, o seu ser natural ou objetivo, e o ser último, o ser do sentido. A distinção entre eles é possibilitada pela reflexão sobre o acesso à sua doação. A coisa material, na medida em que é considerada como sendo, adquire um sentido, em primeiro lugar o sentido objetivo. Enquanto um conteúdo da consciência, em cujos nexos de atos o ser objetivo é posto, simplesmente é, o ser objetivo 'resolve-se' nestes nexos, ou seja, depende deles .

O ser no sentido das ciências objetivas não é "ser último", mas se "resolve" [sich "auflöst"] na "consciência". A própria coisa não se resolve na consciência; ela se resolve em átomos e moléculas. Porém: "Uma coisa é na realidade" e "Há uma realidade" e conhecimentos semelhantes apontam para os nexos da consciência, para as formações da consciência e nelas o ser da coisa e o ser de todos os estados de coisa adquire seu sentido. Um conteúdo imanente, um momento da consciência simplesmente é. Uma coisa, porém, adquire um sentido, é um sentido e todo sentido pressupõe a doação de sentido e pertence a nexos de doação de sentido e de legitimação de sentido, nexos de opinião [Meinung] e de fundamentação da opinião, nos quais o objeto "se encontra" [dasteht], se determina e se legitima como sendo verdadeiramente. Anulemos estes nexos e a fala sobre o ser das coisas perde toda a possibilidade. Não acontece assim com os conteúdos imanentes. Estes são vivenciados e eventualmente vistos e no ver absolutamente presentes. Se são pensados, devem ser também dados de modo imanente. (Hua XXXVI, p.28).

Ser, portanto, é algo que não está 'na' própria coisa ou não é a coisa, mas se lhe atribui ao atribuir-lhe um sentido, ao pensá-la. O que está 'na' coisa, são "átomos e moléculas" de que ela é feita - embora seja difícil falar assim, uma vez que toda afirmação sobre a coisa já implica seu ser consciente. A coisa não é sem ter sentido. Por isso, afirmar o ser de um objeto físico é afirmar a consciência com seus nexos de percepção, de representação e de juízo, que devem ser atuais se por eles o sentido de um ser atual da coisa é pen- 
sado e legitimado. Se examino o modo em que uma coisa é percebida e determinada como tal, concluo que, se a coisa uma casa, por exemplo - é, são necessários tais e tais nexos de consciência, nos quais "consiste" o sentido deste "é" da casa .

"Reconheço assim que esta casa não é precisamente algo ao lado da consciência real e possível, que 'Ela é' significa precisamente que a consciência é e que existem possibilidades da consciência, conformes à lei, nas quais a casa se constitui, nas quais ela é perceptível, determinável, conhecível. O ser da casa não é por assim dizer nada outro que uma outra 'expressão' para a consciência e para as nexos de consciência realmente ocorridos e tal ou tal modo ou nexos possíveis" (Hua XXXVI, p.29).

Ora, a compreensão do que pertence à essência do ser conduz à diferenciação de dois modos fundamentais de ser, a partir da diferenciação dos modos da sua doação no pensamento e da reflexão sobre o que por essência pertence ao ser que assim se dá. Vimos que Husserl escreve sobre isto já nos manuscritos a partir de 1908, quando reflete sobretudo sobre o estatuto do ser empírico; a argumentação sistemática contudo foi exposta pela primeira vez, e assim tornada conhecida, na obra Ideias. Os dois modos de ser ou as duas regiões são ser como realidade ou ser mundano, empírico, e ser como consciência. $\mathrm{O}$ que os distingue é o modo de doação: o ser mundano, cujo sentido é ser transcendente ao pensamento, é dado pela percepção sensível, isto é, numa multiplicidade de perfis, de manifestações ou aparições unilaterais que são unificadas nos atos da consciência numa unidade, não real mas intencional, isto é, pensada, uma "unidade de pensamento" (Hua XXXVI, p. 30). Ser coisa transcendente significa precisamente isso: não poder ser dado absolutamente, plenamente, nos atos de percepção, mas transcendendo os perfis e exigindo ou implicando uma 
infinitude de atos de atestação, de novas doações unificadas no sentido da coisa. A doação da coisa é assim por essência inadequada do ponto de vista epistemológico: nenhuma doação do perfil é suficiente do ponto de vista da sua verificação definitiva, nenhuma unidade já constituída esgota a possibilidade de novas e diferentes doações de perfis e assim a possibilidade de a coisa se mostrar diferente. Isto significa também que a doação empírica não garante absolutamente a existência da coisa, nela a existência não é dada como exigida e necessária, mas sim como por princípio dubitável. Esta caracterização epistemológica resulta assim na compreensão do ser empírico como contingente por essência .

Faz parte, como sabemos, da essência do mundo-de-coisas que nenhuma percepção, por perfeita que seja, dê um absoluto em sua esfera, e a isto está essencialmente ligado que toda experiência, por mais ampla que seja, deixa aberta a possibilidade de que o dado não exista, a despeito da consciência constante da sua presença em carne e osso. Vale aqui a seguinte lei eidética: a existência da coisa jamais é uma existência exigida como necessária pelo dado, mas de certo modo é sempre contingente. Quer dizer: sempre pode ser que o transcurso posterior da experiência obrigue a abrir mão daquilo que já está posto com legitimidade empírica (HuaIII, § 46, p. 97/109).

Por outro lado, a doação da consciência, isto é, das vivências intencionais cujo fluxo é a vida ou o ser da consciência, é por percepção imanente e isto significa sem perfis, sem exibição parcial, ou seja, originariamente e absolutamente: na percepção da vivência, "algo ele mesmo" é apreendido com evidência tal que sua existência não pode ser negada ou duvidada, a doação é absoluta não apenas segundo essência, mas também segundo existência.O ser que se dá assim é o ser absoluto.

Nas Ideias, a partir da análise epistemológica dos modos 
de doação Husserl conclui duas teses de ser:

À tese do mundo, que é uma tese 'contingente', contrapõe-se, portanto, a tese de meu eu puro e da vida do eu, que é uma tese 'necessária', pura e simplesmente indubitável. Toda coisa em carne e osso também pode não ser, mas não um vivido dado em carne e osso: tal é a lei de essência que define essa necessidade e aquela contingência" (HualII, § 46, p.98/109).

A reflexão ulterior sobre os dois modos de ser conduz à explicitação da relação entre eles, nas teses que exprimem o idealismo transcendental: a tese da referência essencial do ser real à consciência e sua dependência da consciência, e a tese da independência da consciência em relação ao ser real. Nas Ideias, o argumento para esta tese é o da aniquilação do mundo: o percurso do nosso fluxo de experiências de fato é tal que elas se harmonizam e confirmam a posição da existência do mundo; mas não é por essência necessário que um mundo seja posto pelo fluxo de vivências, é possível também uma concatenação de percepções tal que nelas o mundo de realidades empíricas não se atesta como idêntico e existente. $O$ ser da consciência numa tal concatenação permanece essencialmente intocado. $O$ ser do mundo é pois por essência apenas um ser intencional, essencialmente relativo à consciência, que por sua vez é e se atesta no seu ser independentemente de haver um mundo ou não. Literalmente Husserl diz:

O ser imanente é, portanto, indubitavelmente ser absoluto no sentido que ele, por princípio, nulla 're' indiget ad existendum. Por outro lado, o mundo da 'res' transcendente é inteiramente dependente da consciência, não da consciência pensada logicamente, mas da consciência atual (Hua III, §. 49, p. 92/115).

O idealismo de Husserl consiste, portanto, a meu ver, na compreensão do sentido último do ser objetivo ou real 
como essencialmente dependente da consciência, isto é, na redução do ser real ao seu sentido de ser real, que é um ser pensado, intencional.

\section{INTERPRETANDO O IDEALISMO DE HUSSERL}

Carlos Alberto Moura, em seu importante estudo Crítica da razão na Fenomenologia, interpreta esta distinção como resultante de duas atitudes diferentes, diferenciadas pelo próprio Husserl, mas entrelaçadas nas suas descrições, sobretudo no texto das Ideias I citado acima: atitude natural ou ingênua e atitude fenomenológica ou transcendental. Para este autor, seria segundo a atitude natural que se faz a distinção entre dois modos de ser, o da consciência e o da realidade, e que se considera o objeto puro e simples como distinto da consciência. Segundo a atitude fenomenológica, por sua vez, que é a consideração sob o ponto de vista da constituição na consciência que está sempre operando em toda a consideração do mundo, a consciência é um todo, é o ser absoluto que inclui em si o Eu e o objeto intencional como polos correlativos. $\mathrm{O}$ objeto puro e simples seria o objeto considerado naturalmente, a coisa enquanto correlato da consciência ingênua; o objeto intencional seria a coisa enquanto correlato da consciência fenomenológica. A afirmação da dependência do mundo em relação à consciência não se referiria, pois, à natureza pura e simples - esta seria uma interpretação essencialmente falsa que provoca o estranhamento do idealismo fenomenológico de Husserl, segundo o autor - mas se refere aos correlatos intencionais.

A epoché, enquanto redução da natureza à subjetividade, não reduz à subjetividade a natureza pura e simples, mas a natureza enquanto fenómeno, que apenas enquanto tal será "inseparável" da consciência. A tese da dependência só ganha sentido em relação à mudança 
de "interesse temático", que dirige o olhar não ao objeto tal como ele é com suas propriedades objetivas, mas ao objeto tal como ele é subjetivamente (MOURA, 1989, p. 209).

A afirmação da dependência da realidade em relação à consciência, segundo este autor, não seria propriamente demonstrada, mas é o resultado da dissolução do 'ser em si' do mundo, o resultado da explicação da constituição transcendental do sentido. A tese da independência da consciência em relação ao mundo puro e simples, por sua vez, seria o resultado do argumento da aniquilação do mundo, referido acima, que evidencia radicalmente o caráter contingente do curso atual das vivências nos quais o mundo se constitui com seu sentido, como também o caráter "intocável" da consciência em toda a mudança do fluxo de vivências.

Como vimos na argumentação acima, Husserl de fato distingue entre a coisa pura e simples e o seu ser objetivo, e entre o ser relativo deste ser objetivo e o ser absoluto da consciência. Ora, como mostra Moura - sem contudo a partir disso rever a explicação das teses do idealismo husserliano - do ponto de vista fenomenológico, não é possível manter a distinção entre o objeto puro e simples e o objeto intencional, não é possível mais falar do objeto puro e simples; ele é fenomenologicamente uma intepretação absolutizante do próprio objeto intencional, e a exterioridade do objeto em relação à consciência é apenas enquanto posta pelos atos de posição da consciência, atos de crença, ele é um sentido constituído. Do ponto de vista fenomenológico, "a natureza é em si mesma subjetiva. Sob esse novo ângulo, o objeto da atitude natural surge como algo de abstraido, o seu objeto "puro e simples" aparece como um subjetivo que foi absolutizado" (MOURA, 1989, p. 213). É enquanto tal, 
enquanto uma abstração ingênua, que ele pode ser justificadamente suspenso pela epoché (MOURA, p. 215).

Do ponto de vista fenomenológico, portanto, a consciência é o ser absoluto, o único ser do qual é possível indubitavelmente afirmar a existência, enquanto o ser do mundo é relativo e dependente da consciência, porque o ser puro e simples dos objetos, pela modificação da atitude natural, é reduzido ao ser intencional. A insistência sobre o objeto puro e simples não mantém no seio da consideração fenomenológica uma consideração natural, não fenomenológica? Segundo Moura, de fato, a consideração fenomenológica não implica a negação total e definitiva da atitude natural. Contudo, parece-me difícil sustentar que o sentido correto do idealismo fenomenológico seja garantido, segundo o próprio Husserl, por uma consideração nãofenomenológica.

Certamente, um esclarecimento mais profundo do que está implicado nas duas atitudes, para Husserl, vem da consideração fenomenológica do que está implicado na doação do ser do ponto de vista subjetivo: toda doação do ser - isto é, todo o preenchimento da intenção que visa o ser - implica uma posição de ser, que é um ato de crença, segundo Husserl. ${ }^{7}$ Ele distingue entre uma crença originária primeira e geral, passiva, que põe o mundo como todo como uma realidade existente, e atos particulares de crença, principalmente de percepção, que se dirigem a objetos singulares e lhes doam o sentido de reais. Tudo o que é objeto existente, uma meta do conhecimento, de ação ou de valoração, só é ente sobre o solo do mundo que por si mesmo, no modo de obviedade, vale como existente (Cfr. HUSSERL, 1939,

${ }^{7}$ Cfr., por exemplo, Hua XXVIII, p. 212. 
p. 25). A redução fenomenológica do ser mundano é necessária, segundo Husserl, porque esta vida subjetiva, que tem na base crença ou posição de ser, sem a redução permanece oculta, acrítica e assim ingênua. Apenas a redução fenomenológica, que precisamente suspende a validade da crença geral no ser do mundo, possibilita a mudança da atitude natural, tornando esta vida acessível, e assim torna possível esclarecer até o fim como as crenças se justificam ou validam através da motivação racional. A verdade, em última instância, será "o correlato do caráter racional perfeito da doxa originária, da certeza da crença” (Hua III, p. $322-$ 323/310); ou seja, o ser é dado como verdade quando a do$x a$ originária tem o caráter racional perfeito. Após a análise fenomenológica de como se justifica a crença no ser real dos objetos mundanos, objetos reais dados por percepção, ao se mostrar a que eles não podem ser dados com doação adequada e completa em nenhuma consciência fechada, mas só podem ser dados de modo perfeito ou total como "ideia no sentido kantiano", conclui-se que o ser verdadeiro da realidade, dos objetos mundanos e do próprio mundo, é uma ideia (Cfr. Hua I, p. 97/99). Também o ser da consciência, de cada vivência, é um ser posto; esta posição, por diferença da posição do ser objetivo, não pode ser racionalmente suspensa ou questionada, é indubitável e por isso absoluta. A vida da consciência transcendental se revela assim como uma nova esfera de ser, o ser originário em relação ao ser do mundo. Contudo, não se trata de duas esferas de ser justapostas, mas de duas considerações da própria subjetividade originária: empírica e transcendental. $\mathrm{O}$ idealismo transcendental se confirma, a meu ver, pela relação entre elas: a realidade mundana é para Husserl um modo necessário da consideração de si mesma da subjetividade 
transcendental que é originária e encerra em si todos os sentidos do ser, também o do seu próprio ser real e mundano. A justificativa do idealismo não se encontra, entretanto, unicamente no ideal de um saber rigoroso que exige o esclarecimento dos fundamentos do saber, como já mencionei, mas também no esforço de Husserl de evitar a perda do sentido do ser, sobretudo da vida humana, por causa da redução de todo saber ao modo de proceder das ciências naturais, cuja consideração do ser é objetivista, positiva, naturalizada. É possível ver no pensamento de Husserl a tentativa de ressaltar o que há de espiritual no ser, no sentido. ${ }^{8}$

Neste sentido, e também além do que foi indicado brevemente aqui, uma ampla e interessante perspectiva ética se abre na fenomenologia de Husserl, pela consideração mais profunda da vida da subjetividade, não apenas teórica, mas valorativa e prática. A vida subjetiva, na medida em que é vida da vontade, tem fins éticos, implica a exigência da auto-responsabilização do sujeito que aspira a ser autêntico na sua relação com a verdade, com o sentido. A vontade e o ânimo, pelo qual se apreende as exigências éticas pessoais, são também uma fonte de posição de ser, visto que também os ideais são um ser (Cfr. Hua XLII, p. 215). Neste sentido e ultimamente, segundo Husserl, há uma exigência prática, ética, de pôr o mundo conforme os ideais e não faz sentido duvidar da existência do mundo se sou um sujeito autêntico, racional, se quero realizar o sentido racional no mundo. A exigência "prática" de agir no mundo com sentido justifica em última instância a crença na existência do mundo (Cfr. Hua XLII, p. 242). Apenas o idealismo corresponde à ideia da humanidade autêntica, autônoma e responsável e à

\footnotetext{
${ }^{8}$ Isto é notável, por exemplo, no texto Crise das ciências humanas e a fenomenologia.
} 
exigência da vida com sentido racional, diz Husserl.

Apenas o idealismo transcendental dá a verdadeira autonomia ao eu e à subjetividade comunicativa (que é o absoluto da humanidade), dá-lhes a força e a sensata possibilidade de autoformação absoluta e da formação do mundo conforme a vontade própria autônoma. (Hua VIII, p. 506).

Não posso aprofundar estes aspectos do idealismo fenomenológico em Husserl. Parece-me que se pode concluir, do que foi dito, que certamente não se trata em Husserl de negar a atitude natural e de negar a existência do ser real; importa-lhe, antes, elucidar o seu sentido e isto é possível em última instância pela investigação fenomenológica da vida da consciência enquanto ser absoluto, em devir. A consideração natural, embora seja necessária para a realização da subjetividade no mundo, contudo não permite a compreensão do sentido originário do ser. É a realização teleológica da subjetividade que exige, tanto do ponto de vista teórico ou epistemológico, quanto do ponto de vista prático, a suspensão da atitude natural e a consideração fenomenológica .

Ao explicitar como se constitui a subjetividade no seu devir, isto é, como se constitui enquanto pessoa, Husserl conclui que o seu ser é devir (Hua VI, p. 272) cuja meta, o telos, é realizável no infinito. Será talvez também em função disto que também a constituição do ser real mundano é infinita, exige um contínuo infinito de aparições, determinado a priori, o que leva Husserl a caracterizar o ser real como a ideia, determinável adequadamente apenas no seu aspecto essencial. 


\section{ProblematizaÇÃO DOS ASPECTOS METAFísicos DO IDEALISMO FENOMENOLÓGICO}

$\mathrm{Na}$ última parte deste trabalho quero refletir sobre os aspectos metafísicos do idealismo de Husserl, nomeadamente sobre a sua compreensão do ser, com a ajuda do que foi pensado sobre o ser na tradição metafísica. Isto, portanto, também é uma consideração não fenomenológica, que não pretende ser uma crítica de Husserl, mas uma reflexão sobre como pensar ainda o sentido do ser.

Um primeiro aspecto que quero destacar é que a diferenciação husserliana de diferentes sentidos ou regiões de ser se inscreve na tradição aristotélica da multiplicidade dos sentidos do ser. Entre os vários sentidos do ser, desde Aristóteles se distingue o ser como verdadeiro e o "ser por si" que é o sentido principal, o ser da ousia e de suas categorias. Ora, para Aristóteles, o ser enquanto verdadeiro, isto é, o ser afirmado nas proposições, não é propriamente objeto da metafísica; a primeira filosofia considera as próprias coisas no seu ser, sobre o qual se fundamenta também o ser verdadeiro. ${ }^{9}$ Claramente a verdade também é a meta da ciência metafísica, na medida em que quanto mais ser tem uma coisa, tanto mais verdade (Metafísica II, 1, 993 b 30). A reflexão sobre a relação entre ser e verdade foi aprofundada na escolástica, quando foi elaborada a doutrina das propriedades transcendentais do ser, entre as quais está a verdade:

\footnotetext{
9 "O verdadeiro é a união do que é realmente unido e a separação do que é separado. [...] Posto que a união e a separação estão na mente e não nas coisas, o ser entendido neste sentido é um ser diferente daquele dos significados eminentes do ser, a saber, a essência, a qualidade, a quantidade ou as outras categorias que o pensamento separa ou reúne; e assim como o ser por acidente, também o ser verdadeiro deve ser deixado de lado: a causa do primeiro é indeterminada, enquanto o segundo consiste numa afecção da mente e ambos se apoiam no restante gênero do ser e não indicam uma realidade subsistente fora da mente" (ARISTÓTELES, Metafísica I, 11027 b 20 1028 a 1$)$.
} 
todo ente, na medida em que é, é verdadeiro, o que significa que é aberto a uma inteligência, isto é, inteligível ou passível de ser conhecido. A verdade diz a relação entre o ente e um intelecto, a verdade do ser é a adequação do ente ao intelecto (divino, em primeiro lugar), em função da qual o intelecto humano finito pode também adequar-se ao ente e formular juízos verdadeiros. Parece-me que a compreensão desta correlação entre o intelecto e a coisa enquanto inteligível é comum à fenomenologia de Husserl e à tradição metafísica aristotélico-tomista. Contudo, nesta última o ser verdadeiro não é o sentido mais fundamental do ser, como disse acima. Ele se fundamenta no sentido do ser como ato de ser do ente. Foi Tomás de Aquino quem desenvolveua distinção entre a essência e o ato de ser no âmago de cada ente $^{10}$; o ato de ser é o que há de mais fundamental em cada coisa que é ${ }^{11}$, é o que não pode ser adequadamente posto em nenhum conceito e não pode confundir-se com o ato de pensamento, pois "o que se oferece ao pensamento quando dizemos é é o ato mesmo de existir, quer dizer, aquela atualidade absoluta que é a existência atual" (GILSON, 1966, p. 184-185). Sobre isto diz Tomás de Aquino claramente: "Ser, com efeito é ato do ente; mas entender não é ato daquilo que é entendido, mas do inteligente [...]" (De Veritate, q. 10 a.8, Resposta para 12). Segundo esta metafísica, portanto, o ato de ser da coisa não pode ser reduzido ao seu ser pensado, porque pertence fundamentalmente à própria coisa e torna possível ela ser compreendida por uma inteligência que diz que a coisa é .

\footnotetext{
${ }^{10}$ Cfr., por exemplo, De ente etessentia, IV, 5, par. 7.

11 "Ora, o ser é o que há de mais íntimo e de mais profundo em todas as coisas, pois é o princípio formal de tudo o que nelas existe." (AQUINO, Summa teologica I q.8, a. 1, respondeo).
} 
Claramente, Husserl recusa precisamente o ser pertencendo "em si" à coisa. Numa observação geral sobre a ontologia escolástica, no texto Fenomenologia como ciência de rigor, Husserl diz que ela se deixa levar pela linguagem, ou seja, pelas palavras e seus significados e deles pretende retirar juízos analíticos, pensando ter conseguido assim conhecimento dos fatos, quando é necessário não se perder nos significados, mas aprofundar-se nos fenômenos ${ }^{12}$.

Contudo, parece-me ser possível argumentar que em relação à própria consciência que pensa o ser, é o seu ato de existir que é o mais fundamental e não pode ser reduzido aos conteúdos pensados por ela. Husserl de fato sublinha em diversos textos que a consciência transcendental não pode ser considerada unicamente na sua essência geral, ela é também e fundamentalmente um fato, isto é, uma consciência individual concreta, e nela a relação entre essência e fato se subvertem:

O ser de um eidos, o ser das possibilidades eidéticas e do universo destas possibilidades, é livre do ser ou do não-ser de uma realização qualquer destas possibilidades, ele é independente no ser de qualquer realidade, nomeadamente a que lhe corresponde. Mas, o eidos do Eu transcendental é impensável sem o Eu transcendental como fático (Hua XV, p. 385).

Devo esclarecer que a consciência fática para Husserl não é necessariamente consciência empírica, isto é, uma consciência existindo realmente num mundo, mas uma consciência individual, um determinado fluxo das vivências obtido pela redução fenomenológica, portanto uma das possibilidades contidas na essência da consciência. ${ }^{13}$ Porém,

\footnotetext{
${ }^{12}$ Hua XXV, p. 20.

13 "Faço aqui de antemão a observação de que falo da consciência fática e não da empírica. [...] A consciência fática é um determinado fluxo de consciência na redução fenomenológica. A pureza Cont.
} 
pensando atentamente o sentido do fático, talvez devamos fazer distinção entre um determinado fático fluxo de consciência, ou seja, uma determinada concatenação de vividos, e o fato de este fluxo, esta consciência, ser ou existir?

Uma conclusão semelhante se encontra nos estudos de Muralt sobre a relação entre os conceitos metafísicos medievais e o pensamento de Husserl. Analisando a noção da intencionalidade do ponto de vista metafísico, isto é, do ser, confrontando-a com as suas origens escolásticas, este autor conclui que a consciência, no seu operar ou ato primeiro, é a própria existência, antes de ser consciência de si ou de exercer qualquer outro ato intencional concreto:

A Leistung primária e originária da razão é a consciência de si, simples e idêntica, que não é em si mesma nem teórica nem prática, mas puramente existencial. [...] $\mathrm{O}$ ato mais simples, portanto primeiro e originário, é, com efeito, para toda realidade, exercer a existência e a unidade. A consciência de si já é, por conseguinte, um ato fundado: ato segundo do ponto de vista existencial, ato primeiro do ponto de vista da constituição. Pois a consciência de si é o ato primeiro e originário da razão enquanto razão que toma consciência da sua existência e de sua unidade e, desse modo, constitui-se como sentido ou essência. - Qualquer outro ato significante é um ato transcendentalmente fundado. A consciência de si só pode ser existencialmente fundada (MURALT, 1998, p. 83) .

Também para consciência, portanto, o ato de ser é o primeiro ato. E, segundo Muralt, por causa da tomada de posição idealista da fenomenologia de Husserl, a única existência real, ou o único ente real no seu ato de ser, acessível à fenomenologia, é a do próprio eu individual.

do método exige que tudo o que é empírico seja posto entre parênteses, ou seja, reduzido ao absoluto, sempre que fazemos considerações a respeito da teoria do conhecimento ou da metafísica. Obviamente, as leis de essência limitam as possibilidades para uma determinada consciência absoluta em geral, mas elas deixam em aberto um número infinito de fatos, de constelações da consciência fática". "O fático é o fluxo da consciência" Cfr. Hua VII, p. 390, 393. 
A compreensão do ser como o ato mais fundamental de cada ente, em primeiro lugar da consciência que considera o mundo, mas também dos próprios entes mundanos, como o seu sentido mais original e íntimo, parece-me importante, capaz de completar a reflexão fenomenológica sobre a relação entre o pensamento e ser. Talvez Husserl se aproxime mais da compreensão do ato de ser da consciência ao compreendê-la como o ser em devir, como um fluxo de vida, ao identificar ser e devir ${ }^{14}$. Esta aproximação entre os aspectos metafísicos da fenomenologia de Husserl e a metafisica aristotélico-tomista sobre o sentido do ser certamente é ainda insuficiente. Contudo, ela permite pensar um sentido do ser que na própria fenomenologia de Husserl, a meu ver, é insuficiente.

Abstract: In a present paper I argue that there is metaphysical dimension of the husserlian Idealism, for it implicates a reflection upon a Being. It is presented the relation between the thinking and the Being in Husserl's Philosophy and the meaning of the Being that results from it; the two regions of Being are the Consciousness, held for the original dimension of Being, from which the worldly or real Being derives as the meaning constituted by the Consciousness. The transcendental Idealism is the unique philosophy capable of explaining the original sense of Being, as response to epistemological and practical demands. Finally I present the sense of Being as act of being, the sense stemming from thomistic Metaphysics, as a possibility to think the sense of Being above the phenomenological Idealism.

Keywords: Idealism, Metaphysics, Being, Thinking.

\section{REFERÊNCIAS}

AQUINO, Tomás. De ente et Essentia. O Ente e a Essência. Trad. Mário Santiago de Carvalho. Covilhã: Universidade da Beira Interior, 2008.

. De Veritate. Questões discutidas sobre a Verdade.

\footnotetext{
${ }^{14}$ Sobre esta identificação, cfr. MURALT, 1974, p. 345-351.
} 
Uberlândia: EDUFU, 2012.

Summa teologica. Suma Teológica. São Paulo: Edições Loyola, 2006.

ARISTÓTELES. Metafísica. Trad. it. Giovanni Reale. Trad. Port. Marcelo Perini. São Paulo: Loyola, 2001.

GHIGI, Nicoletta. La Metafisica in Edmund Husserl. Milano: Franco Angeli, 2007.

GILSON, Etienne. Le Thomisme. Introduction au système de saint Thomas d'Aquin. 6- ed. Paris: Vrin, 1966.

HUSSERL, Edmund. Allgemeine Erkenntnistheorie. Vorlesung 1902/03. (Hua Mat III). Elisabeth Schuhmann(Hsg.). Dordrecht: Springer, 2001.

.Aufsatzeund Vortrage. (1911-1921). (Hua XXV). Thomas Nenon\&Hans Rainer Sepp (Hsg.). Dordrecht: MartinusNijhoff, 1987.

- Cartesianisce Meditationem und Pariser Vorträge. (Hua I). S. Strasser (Hrsg.). Haag: Martinus Nijhoff, 1973. Tradução portuguesa P.M. S. Alves. Meditações cartesianas e Conferências de Paris. Rio de Janeiro: Forense Universitária, 2013.

. Die Idee der Phänomenologie. Fünf Vorlesungen. (Hua II). Walter Biemel (Hrg.). Haag: Martinus Nijhoff, 1950. Trad. Port. Artur Morão. A ideia da Fenomenologia. Cinco Lições. Lisboa: Edições 70, 2000.

.Die Krisis der europäischen Wissennschaften und die transzendentale Phänomenologie.(Hua VI). M. Biemel (Hrsg.). Haag: Martinus Nijhoff, 1954. Tradução portu- 
guesa D. F. Ferrer. A crise das ciências europeias e a fenomenologia transcendental: uma introdução à filosofia fenomenológica. Rio de Janeiro: Forense Universitária, 2012.

. Erfarhung und Urteil. Untersuchungen zur Genealogie der Logik. L. Landgrebe (Hrsg.). Prag: Academia Verlagsbuchhandlung, 1939.

. Erste Philosophie (1923/24). Erster Teil: Kritische Ideengeschichte. (Hua VII). Rudolf Boehm (Hsg). Den Haag: Martinus Nijhoff,. 1956.

. Erste Philosophie, (1923/24). Zweiter Teil. Theorie der phänomenologischen Reduktion.(Hua VIII). Rudolf Boehm (Hrsg.). Den Haag: Martinus Nijhoff, 1959

. Grenzprobleme der Phänomenologie. Analysen des Unbewusstseins und der Instinkte. Metaphysik. Späte Ethik. Texte aus dem Nachlass (1908-1937). (Hua XLII) R.Sowa und Th.Vongehr (Hrsg.). Dordrecht: Springer, 2013.

- Ideen zu einer reinen Phänomenologie und phänomenologischen Philosophie. Erstes Buch: Allgemeine Einführung in die reine Phänomenologie.(Hua III) Haag: Martinus Nijhoff, 1952.Tradução portuguesa M. Suzuki. Ideias para uma fenomenologia pura e para uma filosofia fenomenológica: introdução geral à fenomenologia pura. Aparecida, SP: Ideias\&Letras, 2006.

. »Nachwort«. In: Ideen zu einer reinen Phänomenologie und phänomenologischen Philosophie. Drittes Buch: Die Phänomenologie und die Fundamente der Wissenschaften. (Hua V). Marly Biemel (Hrsg.). Den Haag: Martinus Nijhoff, 1971. 
. Transzendentaler Idealismus. Texte aus dem Nachlass (1908-1921). (Hua XXXVI). Robin D. Rollinger, Rochus Sowa (Hrsg.), Dordrecht: Kluwer Academic Publishers, 2003.

- Vorlesungen über Ethik und Wertlehre.1908-1914 (Hua XXVIII). U. Melle (Hrsg.). The Hague, Netherlands: Kluwer Academic Publishers, 1988.

. Zur Phänomenologie der Intersubjektivität. Dritter Teil: 1929-1935. (Hua XV). Iso Kern (Hsg). Den Haag: Martinus Nijhoff, 1973.

Landgrebe, L. Der Weg der Phänomenologie. Das Problem einer einsprünglichen Erfahrung. Gütersloh: Gutersloher Verlagshaus Gerd Mohn, 1963.

MOURA, Carlos Alberto R., Crítica da razão na fenomenologia. São Paulo: Nova Stella, EDUSP, 1989

MURALT, André de. La métaphysique du phénomène. Paris: Vrin, 1985. Trad. Port. Paula Martins. A metafísica do fenômeno: as origens medievais do pensamento fenomenológico. São Paulo: Ed. 34, 1998.

. L'Idée de la Phénoménologie: L'exemplarisme husserlien. Paris: PUF, 1958. Trad. Garry L. Breckon. The Ideia of Phenomenology. Husserlian exemplarism. Evanston: Northwestern University Press, 1974. 